\title{
Carbohydrate-Based Fat Mimetics Can Affect the Levels of 3-Monochloropropane-1,2-Diol Esters and Glycidyl Esters in Shortbread Biscuits
}

\author{
Anna Sadowska-Rociek ${ }^{1}$ (D) $\cdot$ Ewa Cieślik $^{1}$
}

Published online: 5 March 2019

(C) The Author(s) 2019

\begin{abstract}
Shortbread biscuits have become one of the most desirable snacks in all population groups but due to its high fat content it is searching for new solutions of fat reduction such as the use of carbohydrate-based fat mimetics. However, the thermal processing of food containing lipids in the presence of certain carbohydrates can contribute to the formation of toxic compounds or alter its levels. Therefore, the aim of the study was to evaluate the use of inulin and pectin gels as partial fat replacers (10-40\%) in classical shortbread biscuits in a view of the changes of 3-monochloropropane-1,2-diol ester (3-MCPDE) and glycidyl ester (GE) levels after baking, and also after a two-months storage. The experiment showed that the amount of inulin gel higher than $10 \%$ promoted the endogenous formation of 3-MCPDE probably due to the higher amount of Maillard products formed in the biscuits, but after two months the levels decreased and were comparable with those transferred from shortening. Pectin did not demonstrate such phenomenon, owing to the presence of bound water in gel. Glycidyl esters were partially decomposed during baking and also during storage, particularly in the samples with the addition of pectin gel, which presumably caused by low stability of GE under acidic conditions resulting from the occurrence of galacturonic acid in pectin.
\end{abstract}

Keywords 3-monochloropropane-1,2-diol esters · 3-MCPDE · Glycidyl esters · GE $\cdot$ Fat mimetics $\cdot$ Inulin $\cdot$ Pectin $\cdot$ Shortbread

\begin{abstract}
Abbreviations
3-MCPD 3-monochloropropane-1,2-diol

3-MCPDE 3-monochloropropane-1,2-diol esters

GE glycidyl esters
\end{abstract}

\section{Introduction}

Shortbread biscuits have become one of the most desirable snacks in all population groups due to their low manufacturing cost, more convenience, and long shelf-life, up to 10 months [1]. Nonetheless, the main problem of such products is their

Electronic supplementary material The online version of this article (https://doi.org/10.1007/s11130-019-00723-z) contains supplementary material, which is available to authorized users.

Anna Sadowska-Rociek

a.sadowska-rociek@ur.krakow.pl

1 Malopolska Centre of Food Monitoring, Faculty of Food Technology, University of Agriculture in Krakow, Balicka Street 122, 30-149 Krakow, Poland high fat and sugar content, which turns them into high-calorie products. What is more, food producers usually use less expensive shortenings, which are based on palm fat that is rich in saturated fatty acids, mainly palmitic acid [2]. High quantities of saturated lipids have been associated with serious health problems such as obesity, cancer, high blood cholesterol and coronary heart diseases [3-5]. Therefore, the formulation of low-fat products has become a high priority for food industry. In addition, nowadays consumers are much more concerned about their health and demand food of natural origin, conferring also health benefits. Hence, it is searching for new solutions to produce pro-health foods that meet the consumers' expectations $[3,6,7]$.

In shortbread fat plays an important role in improving palatability, texture and flavour and its fully replacement has become a challenge for scientists and food technologists [8]. There are different approaches for saturated fat reduction in bakery items, such as substitution with vegetable oils or the use of fat mimetics (protein- and carbohydrate- based) - gel-like matrices that are formed at the presence of substantial levels of water, resulting in lubricant and flowing properties similar to those of fats [4]. Recently, the use of 
carbohydrate-based fat mimetics such as inulin or pectin has become a popular concept of fat level reduction in bakery products. Inulin is a heterogeneous blend of fructose polymers derived from chicory root, garlic, wheat, bananas, and artichokes. It has been reported as a potential ingredient to imitate the functional and sensorial properties of fat and sugar, at the same time providing high-quality baked products with considerably fewer calories [8]. Inulin also possesses prebiotic properties, which are linked to a variety of beneficial physiological effects as improving bowel habits, increasing calcium absorption, lowering of serum lipids, a positive effect on feeling of satiety, and stimulating the immune system [9]. Up to now, inulin has been successfully applied as a fat replacer even up to $50 \%$ without any substantial changes in sensory characteristics of cookies [8, 10]. Pectins, the methyl esters of polygalacturonic acid and its salts, are complex natural carbohydrates found in plant cell walls, especially in apples and citrus fruits. Due to strong gelling and thickening properties, pectin has been used extensively in a variety of foods in order to control the texture and rheology. Another advantage of pectin is good stability in high temperatures $[11,12]$. Its beneficial health effects such as anti-inflammatory, anti-cancer, and hypocholesterolemic activities have also been reported. So far, pectins were evaluated as an effective fat replacer in biscuits up to $30 \%$ without a loss of quality $[13,14]$.

The presence of vegetable fat such as palm oil in food is also related to the risk of the occurrence of some contaminants that can be transferred with fat to food products. It has been shown that refined edible oils might contain high levels of esters of higher fatty acids and 3-chloropropane1,2-diol (3-MCPD) (3-MCPD esters, 3-MCPDE) or glycidol (glycidyl esters, GE). These compounds, which are similar in their structure to lipids, are formed during refining of vegetable oil $[15,16]$. According to EFSA report [17], the ester levels in vegetable fats range from 181 to $2912 \mu \mathrm{g} \mathrm{kg}^{-1}$ (3-MCPDE, expressed as free 3-MCPD) and from $114 \mu \mathrm{g} \mathrm{kg}^{-1}$ to as much as $3955 \mu \mathrm{g} \mathrm{kg}^{-1}$ (GE, expressed as glycidol moiety). Therefore, partially replacement of vegetable fat with other substances in bakery items can be a simple mean for the decreasing MCPDE and GE in human diet. On the other hand, the formation of esters during thermal processing of food has been reported recently [18]. Thus, the occurrence of esters in bakery commodities can origin from bakery fat or the compounds can be generated during heat treatment. However, no such study for bakery items with reduced fat level has been performed in available literature.

For that reason, in the presented paper we decided to evaluate the use of inulin and pectin as partial fat replacers (10$40 \%$ ) in classical shortbread biscuits in a view of the changes of 3-MCPDE and GE levels after baking, and also after twomonths storage.

\section{Materials and Methods}

Biscuit Ingredients Inulin (derived from chicory root) was purchased from Intenson, Poland. Apple pectin (nonamidated) was delivered by Naturex Group, Poland. Other biscuit ingredients (wheat flour type 500, bakery fat, eggs, sucrose) were purchased from a local supermarket. The bakery fat (total fat level 80\%) contained sunflower and rapeseed oil in varying proportions, palm oil, rapeseed oil partially hydrogenated, water, acidified milk, salt $(0.3 \%)$, sugar, emulsifiers (mono- and diglycerides of fatty acids, mono- and diglycerides of fatty acids esterified with citric acid, sunflower lecithin), aroma, annatto, citric acid, vitamins $\mathrm{A}_{\text {and }} \mathrm{D}_{3}$ (according to the manufacturer).

Formulation of Biscuits The biscuit formulation was based on a standard shortbread recipe (Table 1). For bakery fat substitution inulin (samples marked as "I") or pectin ("P") gels were prepared by dispersing inulin and pectin powders in distilled water, at the minimum concentrations that resulted in gel formation: $60 \%(w / w)$ for inulin and $20 \%$ for pectin. The gels were further used as fat replacement at following quantities: 0 (control), 10,20,30, and 40\%. Therefore, 9 biscuit recipes were prepared, each in four independent replicates. After thorough mixing all ingredients, the dough was cut into $0.5 \mathrm{~cm}$ thick discs of $5 \mathrm{~cm}$ diameter, weighed, and then baked at $200{ }^{\circ} \mathrm{C}$ for $10 \mathrm{~min}$ in a Hendi G5D convection steam oven (Hendi Food Service Equipment, Netherlands). After baking, the biscuits were cooled to ambient temperature, weighed once again, and divided into two groups. The first group was analysed immediately after baking, while the second group of biscuits was packed in polyethylene bags, tightly sealed and stored for two months. The storage experiment was conducted in an airconditioned laboratory under storage conditions according to the standard [19].

Determination of 3-MCPDE and GE Determination of 3MCPD esters and glycidyl esters was performed in all samples of biscuits, immediately after baking and after a twomonths storage period. All dough ingredients were also analysed for 3-MCPDE and GE levels. The extraction and determination of fat was performed using $\mathrm{CO}_{2}$ in critical phase, according to the procedure formerly developed and validated [20]. The extracted fat was spiked with $270 \mu \mathrm{L}$ of PP-3-MCPD- $\mathrm{d}_{5}$ and P-Gly- $\mathrm{d}_{5}$, used as internal standards. Further steps were performed according to the procedures described previously [20].

Determination of Water Content Water content of the biscuits was determined by the weight-loss method as described in the standard [21]. The samples were dried in an oven at $130{ }^{\circ} \mathrm{C}$ until constant weight was achieved. 
Table 1 Dough ingredients used in examined variants of the biscuits in the study

\begin{tabular}{|c|c|c|c|c|c|c|c|c|c|}
\hline \multirow[t]{2}{*}{ Ingredients [g] } & \multirow[t]{2}{*}{ Control (K) } & \multicolumn{4}{|c|}{ Biscuits with inulin } & \multicolumn{4}{|c|}{ Biscuits with pectin } \\
\hline & & $\begin{array}{l}10 \% \\
\text { (I 10) }\end{array}$ & $\begin{array}{l}20 \% \\
\text { (I 20) }\end{array}$ & $\begin{array}{l}30 \% \\
\text { (I 30) }\end{array}$ & $\begin{array}{l}40 \% \\
\text { (I 40) }\end{array}$ & $\begin{array}{l}10 \% \\
\text { (P 10) }\end{array}$ & $\begin{array}{l}20 \% \\
\text { (P 20) }\end{array}$ & $\begin{array}{l}30 \% \\
\text { (P 30) }\end{array}$ & $\begin{array}{l}40 \% \\
\text { (P 40) }\end{array}$ \\
\hline Wheat flour & 300 & 300 & 300 & 300 & 300 & 300 & 300 & 300 & 300 \\
\hline Bakery fat & 200 & 180 & 160 & 140 & 120 & 180 & 160 & 140 & 120 \\
\hline Inulin gel & - & 20 & 40 & 60 & 80 & - & - & - & - \\
\hline Pectin gel & - & - & - & - & - & 20 & 40 & 60 & 80 \\
\hline Sucrose & 100 & 100 & 100 & 100 & 100 & 100 & 100 & 100 & 100 \\
\hline Yolk eggs & 3 & 3 & 3 & 3 & 3 & 3 & 3 & 3 & 3 \\
\hline
\end{tabular}

Changes of Fat Replacers upon Heat Treatment $200 \mathrm{mg}$ of pectin and inulin gels were heated at $200{ }^{\circ} \mathrm{C}$ for $10 \mathrm{~min}$. After cooling, the resulting residues were weighted and $10 \mathrm{~mL}$ of deionised water was added; the samples were vortexed for $2 \mathrm{~min}$ and filtered with a filter paper. The extracts were further used for the determination of $\mathrm{pH}$ level. $\mathrm{pH}$ level was also determined for raw inulin and pectin at the concentration of $2 \%(w / w)$.

\section{Results and Discussion}

The Changes of the Ester Levels during Baking The 3-MCPDE level in the fat phase of bakery fat was equal to $905 \pm$ $15 \mu \mathrm{g} \mathrm{kg}^{-1}$ (mean and standard deviation of four independent replicates), while the glycidyl esters reached $446 \pm 21 \mu \mathrm{g} \mathrm{kg}^{-1}$ (expressed as glycidol moiety). Other dough ingredients were free of examined esters. The fat amount in baked biscuits ranged from 17.3 to $26.2 \%(w / w)$, with the highest level found in the control sample and the lowest one in the samples with the use of $40 \%$ of fat replacer, which was in good agreement with the values calculated theoretically (Fig. 1S and Fig. 2S Supplementary Material). Based on these results, it was established that the baked biscuits (including also the loss of water during baking) should contain from 166 to $263 \mu \mathrm{g} \mathrm{kg}^{-1}$ of 3-MCPDE and $82-130 \mu \mathrm{g} \mathrm{kg}^{-1}$ of GE and the amount of both esters should decrease with the reduction of the shortening content (Figs. 1, 2, 3, and 4). Meanwhile, the highest amount of 3-MCPDE was detected in the sample that contained $20 \%$ of inulin gel instead of fat (I20, $277 \mu \mathrm{g} \mathrm{kg}^{-1}$ ); the lowest level was discovered in the sample with $20 \%$ of pectin (P20) and was equal to $130 \mu \mathrm{g} \mathrm{kg}^{-1}$. Glycidyl ester levels ranged from $54 \mathrm{\mu g} \mathrm{kg}^{-1}$ (I40) to $131 \mu \mathrm{g} \mathrm{kg}^{-1}$ (control sample).

The levels of glycidyl esters were significantly lower ( $p<0.05$ in one-way analysis of variance) from the calculated theoretically values in all samples, except for the sample I10. The most significant difference (at about 34\%) was observed in the sample P40. No increase in GE amount during baking was observed. GE slightly increased only in the control sample, at about $6 \%$. The amount of GE detected in the samples was well correlated with the decreasing amount of bakery fat (correlation coefficient equal to 0.97 and 0.93 for the samples with inulin and pectin, respectively). This implies that glycidyl esters were partially decayed during baking, and probably no other factors affected this process.

For the 3-MCPD esters its levels differed significantly from the theoretical values in almost all investigated samples, except for the sample P40. In three samples with inulin gel (I20, I30, I40) the 3-MCPDE amount raised, and for the sample I40 this increase was equal to $57 \%$. On the contrary, in the control sample and the samples with pectin gel (P10, P20, P30) the decrease in 3-MCPD content was reported and the most substantial change was observed for the control and P20 (40\%). What is more, no correlation between fat amount and 3MCPDE levels similar to those reported for GE was noted. This indicates that the 3-MCPD esters present in bakery fat were transferred to dough but high temperatures and the presence of inulin and pectin altered its level. Indeed, the inulin gel in the amounts higher than $20 \%$ contributed to increased levels of 3-MCPDE, which were even higher than those observed in the control sample. This phenomenon suggests that the presence of inulin can lead to the additional formation of 3-MCPDE.

Among the samples with the use of pectin gel the levels of 3-MCPDE were comparable. No statistically significant differences were observed between the 3-MCPD amounts in the control sample and the samples with the pectin gel. Hence, in the control sample, the 3-MCPD esters were probably partially decayed during baking and in the rest of the samples with pectin the degradation also occurred, but in the latter case the degradation process was slower.

The Changes of Water, Fat and Ester Levels after Storage The amount of water as well as fat content did not change significantly during two months of storage (Fig. 1S, 2S and 3S Supplementary Material), while in the case of 3-MCPD esters statistically significant changes were observed for all samples 
Fig. 1 The content of 3-MCPDE (expressed as free 3-MCPD) in the biscuits with the inulin gel addition; initial - the levels of 3MCPDE transferred from the bakery fat to biscuits (calculated theoretically); $0 \mathrm{~m}$ - the levels of 3-MCPDE in the biscuits after baking; $0 \mathrm{~m}$ - the levels of 3MCPDE in the biscuits after a two-months storage; error bar is a confidence interval $(95 \%)$

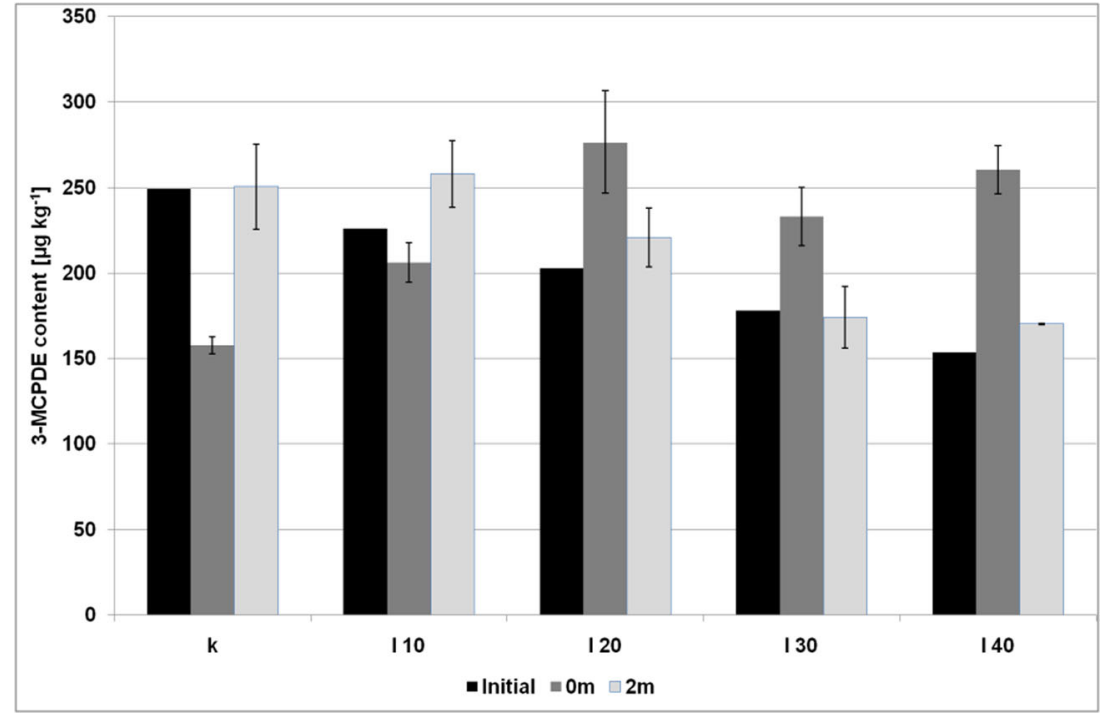

with the use of inulin (Fig. 1). The amount of 3-MCPDE increased about 59 and $25 \%$ for the control sample and the sample I10, respectively, while for the rest of the samples (I20, I30, I40), the contents of 3-MCPDE were lower than before the period of two months, and, surprisingly, were roughly comparable to those calculated from bakery fat. The most significant decrease was discovered for the sample I40 (35\%). It appears therefore that the 3-MCPD esters were decayed upon storage probably with the release of free 3MCPD. In opposite to these findings, among the samples with pectin only the sample P40 exhibited significant change in the level of 3-MCPDE - an increase at about 20\%, comparing to the amount after baking (Fig. 2). Glycidyl esters decreased significantly in the control sample, all samples with the addition of pectin and in the samples I10 and I20 (Figs. 3 and 4). GE amount maintained at the same level after storage only in the samples with the level of inulin higher than $20 \%$.
Influence of Inulin and Pectin on 3-MCPDE and GE Levels Differentiated levels of 3-MCPDE and GE resulting from the use of two fat mimetics can be explained by its physicochemical properties and its changes upon heat treatment. In order to explain the changes in its properties during thermal processing, inulin and pectin gels were submitted to heating at $200{ }^{\circ} \mathrm{C}$ for $10 \mathrm{~min}$ and then $\mathrm{pH}$ level was measured. $\mathrm{pH}$ values of raw inulin ( $2 \%$ solution) was equal to $5.52 \pm 0.09$ but after heating it decreased to $4.21 \pm 0.15$ as the effect of thermal degradation of sugars. $\mathrm{pH}$ of raw pectin was significantly lower $(2.08 \pm 0.15)$, which resulted mainly from the presence of galacturonic acid. After heating $\mathrm{pH}$ did not change significantly and was equal to $1.95 \pm 0.11$.

Differences in loss of mass during heating were another interesting observation. In the case of inulin gel, which contained $60 \%$ dried inulin and $40 \%$ water, the loss of mass was reported to be about $63 \%$. This value resulted
Fig. 2 The content of 3-MCPDE (expressed as free 3-MCPD) in the biscuits with the pectin gel addition; initial - the levels of 3MCPDE transferred from the bakery fat to the biscuits (calculated theoretically); $0 \mathrm{~m}$ - the levels of 3-MCPDE in the biscuits after baking; $0 \mathrm{~m}$ - the levels of 3MCPDE in biscuits after a twomonths storage; error bar is a confidence interval $(95 \%)$

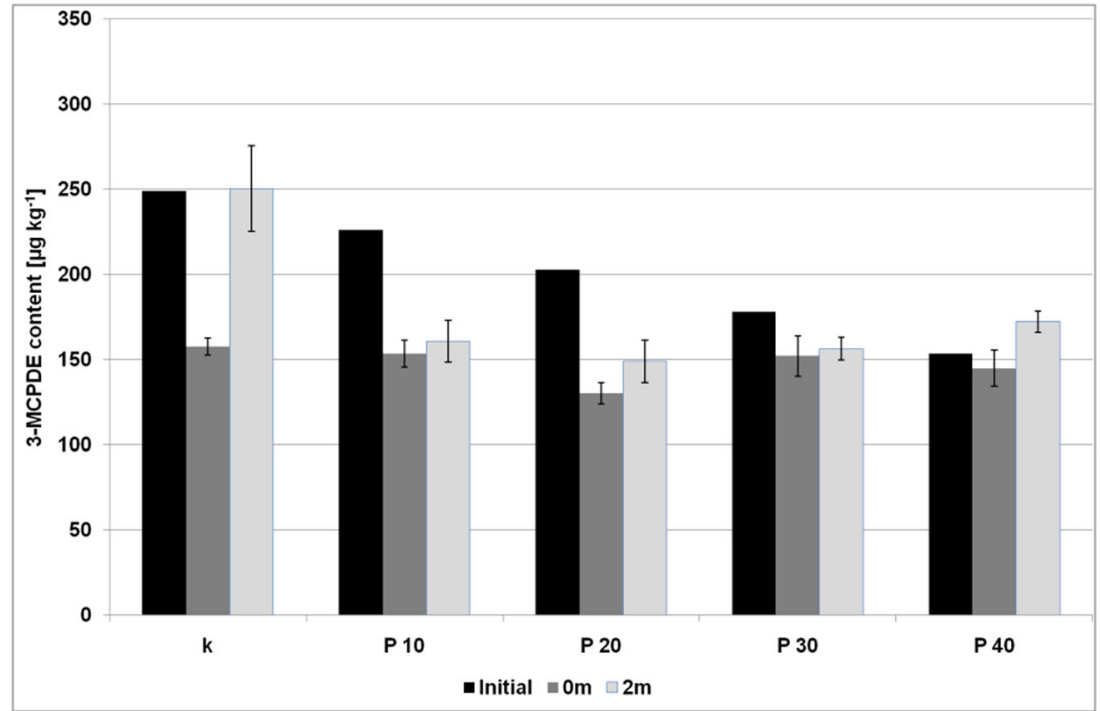


Fig. 3 The content of GE (expressed as glycidol moiety) in the biscuits with the inulin gel addition; initial - the levels of GE transferred from the bakery fat to the biscuits (calculated theoretically); $0 \mathrm{~m}$ - the levels of GE in the biscuits after baking; $0 \mathrm{~m}-$ the levels of GE in the biscuits after a two-months storage; error bar is a confidence interval $(95 \%)$

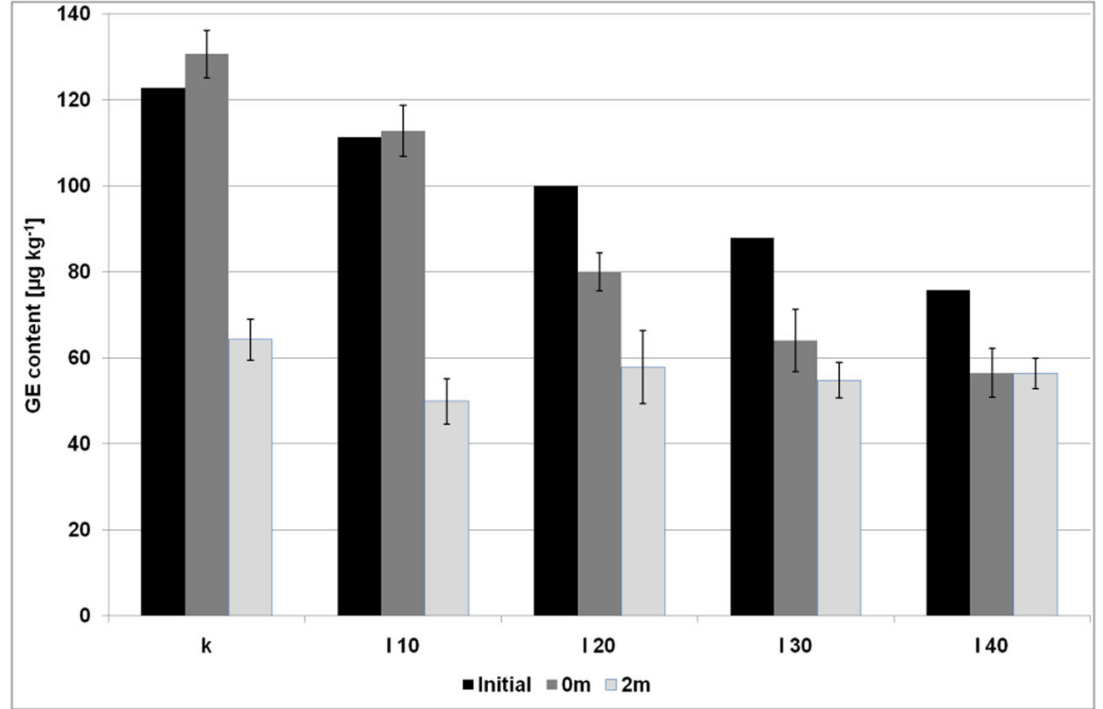

not only from the water evaporation but could also arise from the thermal degradation of inulin. For pectin gel although it contained more water $(80 \%)$ and less dried pectin (20\%), the loss of mass was only about $20 \%$, which means that upon heating water was not completely evaporated and still remained in the gel. Therefore, it can be concluded that pectin gels are more effective in binding water and are more stable to high temperatures, in contrary to inulin. Inulin is composed with long fructose chains, which during thermal treatment are readily decomposed to new products, mainly fructose and di-D-fructose dianhydrides [22, 23]. This process accelerates the non-enzymatic browning of dough leading to the formation of Maillard compounds $[24,25]$. Therefore, the biscuits with higher levels of inulin usually show darker colour, which was also observed in this study, especially for the sample with $40 \%$ use of inulin. Maillard compounds and organic acids, which are formed from reducing sugars, are also supposed to promote the formation of 3-MCPD in food [26]. Pectin is whereas much more stable during heating and, additionally, it has been observed that hydrocolloids based on pectin are able to maintain water and can also inhibit the formation of Maillard compounds [13, 27]. Therefore, the cakes with the use of pectin as fat replacer usually show lighter colour [13]. This observation was also noticed in this experiment, but only for the sample with $40 \%$ use of pectin. Apart from lower Maillard product formation higher water activity in the samples with pectin could probably prevent from the endogenous formation of the 3-MCPDE upon heating.

On the other hand, low $\mathrm{pH}$ level of pectin might be a potential explanation for the decay of glycidyl esters during heating and storage. It is well known that GE are unstable due to the presence of an epoxide group in its structure, which can be destructed under acidic conditions [16]. Hence, the acids in
Fig. 4 The content of GE (expressed as glycidol moiety) in the biscuits with the pectin gel addition; initial - the levels of GE transferred from the bakery fat to the biscuits (calculated theoretically); $0 \mathrm{~m}$ - the levels of GE in the biscuits after baking; $0 \mathrm{~m}$ - the levels of GE in the biscuits after a two-months storage; error bar is a confidence interval (95\%)

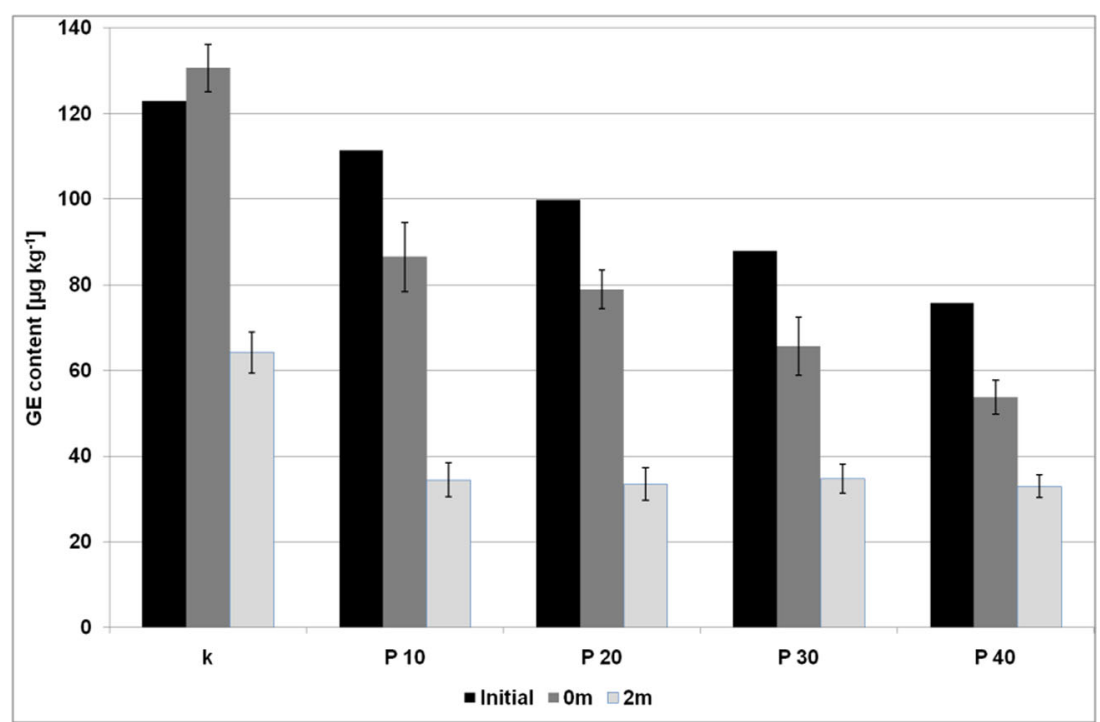


the samples with the addition of pectin might accelerate the degradation of glycidyl esters upon storage. Decay of GE over a period of few months has already been reported [28].

\section{Conclusions}

The obtained results reveals that the presence of inulin or pectin added instead of some fat amount can influence on the levels of 3-MCPDE and GE in shortbread during its baking and storage. The amount of inulin higher than $10 \%$ can promote the endogenous formation of 3-MCPD esters. However, the esters in the samples with higher amount of inulin are decayed during a longterm storage. Second investigated fat replacer, pectin, does not demonstrate such phenomenon; no endogenous formation of 3-MCPDE has been observed and the levels of 3-MCPDE were more stable during storage. Presented experiment also indicates that the presence of acids can influence on GE amount in shortbread, while water has a substantial impact on the amount of 3-MCPDE.

From consumers' point of view, the partial replacement of bakery fat with inulin or pectin can be an effective mean to decrease high energy value of shortbread and eliminate the presence of saturated fat from the diet. Both inulin and pectin have many pro-healthy properties which make them an interesting ingredient for many food products. However, regarding thermal degradation of the inulin it should be emphasized that consumption of the thermal processed products containing more than $20 \%$ inulin use as fat replacer should not be recommended.

Funding This study was funded by Ministry of Science and Higher Education of Republic of Poland within the statutory R \& D activities (DS-3707/17/KTGiK).

\section{Compliance with Ethical Standards}

Conflict of Interest Anna Sadowska-Rociek and Ewa Cieślik declare that they have no conflict of interest and this article does not contain any studies with human participants or animals.

Open Access This article is distributed under the terms of the Creative Commons Attribution 4.0 International License (http:// creativecommons.org/licenses/by/4.0/), which permits unrestricted use, distribution, and reproduction in any medium, provided you give appropriate credit to the original author(s) and the source, provide a link to the Creative Commons license, and indicate if changes were made.

Publisher's Note Springer Nature remains neutral with regard to jurisdictional claims in published maps and institutional affiliations.

\section{References}

1. Koczoń P et al (2016) The change of fatty acids composition of polish biscuits during storage. Food Chem 202:341-348. https:// doi.org/10.1016/j.foodchem.2016.02.019

2. Onacik-Gür S, Zbikowska A, Jaroszewska A (2015) Effect of higholeic sunflower oil and other pro-health ingredients on physical and sensory properties of biscuits. CYTA - J Food 13:621-628. https:// doi.org/10.1080/19476337.2015.1032358

3. Rodríguez-García J, Salvador A, Hernando I (2014) Replacing fat and sugar with inulin in cakes: bubble size distribution, physical and sensory properties. Food Bioprocess Technol 7:964-974. https://doi.org/10.1007/s11947-013-1066-z

4. Dapcevic-Hadnadev T, Hadnadev M, Pojic M, Rakita S, Krstonošic V (2015) Functionality of OSA starch stabilized emulsions as fat replacers in cookies. J Food Eng 167:133-138. https://doi.org/10. 1016/j.jfoodeng.2015.02.002

5. WHO (2018) Obesity and overweight. World Health Organization (WHO), Geneva

6. Nagi HPS, Kaur J, Dar BN, Sharma S (2012) Effect of storage period and packaging on the shelf life of cereal bran incorporated biscuits. Am J Food Technol 7:301-310. https://doi.org/10.3923/ ajft.2012.301.310

7. Mofasser Hossain AKM, Brennan MA, Mason SL et al (2017) The combined effect of blackcurrant powder and wholemeal flours to improve health promoting properties of cookies. Plant Foods Hum Nutr 72:280-287. https://doi.org/10.1007/s11130-017-0619-0

8. Rodríguez-García J, Laguna L, Puig A, Hernando I (2013) Effect of fat replacement by inulin on textural and structural properties of short dough biscuits. Food Bioprocess Technol 6:2739-2750. https://doi.org/10.1007/s11947-012-0919-1

9. Topolska K, Radzki RP, Filipiak-Florkiewicz A et al (2018) Fructan-enriched diet increases bone quality in female growing rats at calcium deficiency. Plant Foods Hum Nutr 73:172-179. https:// doi.org/10.1007/s11130-018-0671-4

10. Giarnetti $\mathrm{M}$ et al (2015) Fat replacement in shortbread cookies using an emulsion filled gel based on inulin and extra virgin olive oil. LWT-Food Sci Technol 63:339-345. https://doi.org/10.1016/j. lwt.2015.03.063

11. Fraeye I et al (2007) Influence of pectin properties and processing conditions on thermal pectin degradation. Food Chem 105:555563. https://doi.org/10.1016/j.foodchem.2007.04.009

12. Aburto J, Moran M, Galano A, Torres-García E (2015) Nonisothermal pyrolysis of pectin: a thermochemical and kinetic approach. J Anal Appl Pyrol 112:94-104. https://doi.org/10.1016/j. jaap.2015.02.012

13. Lim J, Ko S, Lee S (2014) Use of yuja (Citrus junos) pectin as a fat replacer in baked foods. Food Sci Biotechnol 23:1837-1841. https://doi.org/10.1007/s10068-014-0251-9

14. Prihatin A, Shiguo C, Xingqian Y (2015) Pectin-enriched material from mandarin orange byproducts as a potential fat replacer in cookies. Int J Adv Sci Eng Inf Technol 5:31-35

15. Šmidrkal J et al (2016) Mechanism of formation of 3-chloropropan1,2-diol (3-MCPD) esters under conditions of the vegetable oil refining. Food Chem 211:124-129. https://doi.org/10.1016/j. foodchem.2016.05.039

16. Cheng W, Liu G, Wang L, Liu Z (2017) Glycidyl fatty acid esters in refined edible oils: a review on formation, occurrence, analysis, and elimination methods. Compr Rev Food Sci Food Saf 16:263-281. https://doi.org/10.1111/1541-4337.12251

17. EFSA (2016) Risks for human health related to the presence of 3and 2-monochloropropanediol (MCPD), and their fatty acid esters, and glycidyl fatty acid esters in food. EFSA J 14:4426-4585. https://doi.org/10.2903/j.efsa.2016.4426 
18. Sadowska-Rociek A (2019) The effects of adding "flavor enhancers" on levels of chloropropanediol esters and glycidyl esters in savoury shortbread. Eur Food Res Technol 245:489-498. https://doi.org/10.1007/s00217-018-3180-7

19. Polish Committee for Standardization (1994) PN-A-74859:1994 preserved pastry goods - packaging, storage and transport. PKN, Warsaw

20. Sadowska-Rociek A, Cieślik E, Florkiewicz A (2018) Formation of free and bound 3-monochloropropane-1,2-diol in fat-rich cereal model systems: the impact of flour composition. Chem Pap 72: 497-507. https://doi.org/10.1007/s11696-017-0302-9

21. AOAC (2005) Solids (total) and moisture in flour, method 925.10. In: Official methods of analysis, 18th edn. AOAC International, Gaithersburg

22. Trabs K, Kasprick N, Henle T (2009) Isolation of reaction products resulting from heat-induced degradation of inulin. Czech J Food Sci 27:166-168. https://doi.org/10.17221/921-CJFS

23. Bohm A, Kaiser I, Trebstein A, Henle T (2005) Heat-induced degradation of inulin. Eur Food Res Technol 220:466-471. https://doi. org/10.1007/s00217-004-1098-8
24. Poinot $P$ et al (2010) Influence of inulin on bread: kinetics and physico-chemical indicators of the formation of volatile compounds during baking. Food Chem 119:1474-1484. https://doi.org/10. 1016/j.foodchem.2009.09.029

25. Bojnanska T, Tokar M, Vollmannova A (2015) Rheological parameters of dough with inulin addition and its effect on bread quality. $\mathrm{J}$ Phys Conf Ser 602:012015. https://doi.org/10.1088/1742-6596/ $602 / 1 / 012015$

26. Sadowska-Rociek A, Cieślik E, Sieja K (2017) Mitigation role of erythritol and xylitol in the formation of 3-monochloropropane-1,2-diol and its esters in glycerol and shortbread model systems. Eur Food Res Technol 11:2055-2063. https://doi.org/10.1007/s00217-017-2916-0

27. Zeng $X$ et al (2010) Activities of hydrocolloids as inhibitors of acrylamide formation in model systems and fried potato strips. Food Chem 121:424-428. https://doi.org/10.1016/j.foodchem. 2009.12.059

28. Samaras VG, Giri A, Zelinkova Z, Karasek L, Buttinger G, Wenzl T (2016) Analytical method for the trace determination of esterified 3and 2-monochloropropanediol and glycidyl fatty acid esters in various food matrices. J Chromatogr A 1466:136-147. https://doi.org/ 10.1016/j.chroma.2016.08.071 